\title{
Sofrimento e Violência que a Lógica Proibicionista Gera na Vida de Usuários de Drogas I lícitas
}

\section{Suffering and Violence that Prohibitionist Logic Gets in the Lives of Illicit Drug Users}

\section{Sufrimiento y Violencia que la Lógica Prohibicionista Genera en la Vida de Usuarios de Drogas I lícitas}

\author{
Bárbara Santos Bernardino da Silva* \\ Faculdade Frassinetti do Recife - Fafire, Recife, Pernambuco, Brasil \\ Paulo J osé Barroso de Aguiar Pessoa** \\ Faculdade Frassinetti do Recife - Fafire, Recife, Pernambuco, Brasil
}

\begin{abstract}
RESUMO
A proibição do uso de drogas é um fenômeno essencialmente moderno, pautada numa postura intolerante e repressiva, um discurso de terror e punição que acaba por gerar violência e sofrimento para os usuários de substâncias ilícitas. Mostramos por meio de alguns teóricos o quanto os discursos e práticas ideologizados colocam as pessoas que utilizam drogas ilícitas como inimigos sociais sem considerar as contradições e riscos a que são submetidos cotidianamente, além de ir em direção oposta à tendência à atualização e ao potencial do indivíduo. O presente estudo se caracteriza por ser uma pesquisa bibliográfica, de cunho qualitativo. A literatura consultada sugere que o fenômeno das drogas é complexo e se configura como pertencente à condição humana, bem como o único meio de contribuir com a ampliação de sentidos existências é por meio da política de Redução de Danos.
\end{abstract}

Palavras-chave: proibicionismo, sofrimento, violência, redução de danos.

\begin{abstract}
The prohibition of drug use is an essentially modern phenomeno, based on an intolerant and repressive stance, a discourse of terror and punishment, which generates violence and suffering to users of illicit substances. We have shown through some theorists how ideological discourses and practices place people who use illicit drugs as social enemies without considering the contradictions and risks they are submitted daily, in addition to going in the opposite direction as to the tendency to update and the potential of the individual. The present study is characterized by a qualitative bibliographical research. With the elaboration of such a study it is able to perceive that the phenomenon of drugs is complex, and is configured as belonging to the condition, as well as the only way to contribute to the expansion of existent senses is through the Harm Reduction policy.
\end{abstract}

Keywords: prohibition, suffering, violence, harm reduction. 


\begin{abstract}
RESUMEN
La prohibición del uso de drogas es un fenómeno esencialmente moderno, pautado en una postura intolerante y represiva, un discurso de terror y castigo que acaba por generar violencia y sufrimiento para los usuarios de sustancias ilícitas. Mostramos por medio de algunos teóricos cuánto los discursos y prácticas ideologizados colocan a las personas que utilizan drogas ilícitas como enemigos sociales sin considerar las contradicciones y riesgos a que son sometidos cotidianamente, además de ir en dirección opuesta a la tendencia a la actualización y al potencial del individuo. El presente estudio se caracteriza por ser una investigación bibliográfica, de cuño cualitativo. La literatura consultada sugiere que el fenómeno de las drogas es complejo, y se configura como perteneciente a la condición humana, así como el único medio de contribuir con la ampliación de sentidos existencias es por medio de la política de Reducción de Daños.
\end{abstract}

Palabras clave: prohibicionismo, el sufrimiento, violencia, reducción de daños.

$\mathrm{O}$ ato de ingerir algum tipo de substância psicoativa, as chamadas drogas, a fim de alterar o comportamento, o humor, como também para fins medicinais bem como se conectar com o transcendente, são utilizadas pelos humanos desde o início da civilização (Freitas, 2016). Nesta concepção, o café, o chá, o álcool, o crack, maconha, entre outras, são substâncias que alteram o funcionamento do organismo, produzem euforia, alucinações, insônia, tranquilização, irritabilidade, inapetência, dentre outros (Masur \& Carlini, 1993).

No ponto de vista da antropóloga Xiberras (1989), as substâncias psicotrópicas trazem potencialmente em si o poder de decuplicar as capacidades humanas ocasionando sensações caracterizadas pela euforia ou disforia. Na concepção da psicologia, quando pensamos em drogas, temos de pensar em quatro vertentes - produção, comércio, uso e dependência, para no mínimo, poder dialogar com o tema das drogas ilícitas (Gorgulho, 2012); Sodelli (2010) vai mais além. Para ele, a relação que o indivíduo estabelece com a droga é única se revelando por meio da relação do homem com o mundo, e por meio desse contexto é que se estabelece o sentido do uso.

De maneira geral, as drogas foram classificadas em licitas ou ilícitas, mas ao longo da história tal classificação vem sofrendo alterações, isto é, drogas que antes eram liberadas hoje se tornaram proibidas. Ou seja, as drogas lícitas tem a comercialização autorizada e as drogas ilícitas a comercialização é proibida (Sodelli, 2010). Ainda segundo Sodelli (2010), a proibição é um fenômeno essencialmente moderno, chamado de lógica proibicionista; que nem sempre está diretamente relacionado com a saúde coletiva, mas com o contexto político que esta proibição quer propiciar ou reprimir. A postura proibicionista tem estado cada vez mais presente nos meios sociais, mídias e políticas públicas, manifestando um discurso de terror e de punição a cidadãos usuários de substâncias ilícitas. 
A partir do Relatório Mundial sobre Drogas (Unodc, 2015), uso das substâncias continua estável em todo o mundo, cerca de um pouco mais de $5 \%$ da população mundial, com idades entre 15 e 65 anos, tem feito uso de algum tipo de droga ilícita. No entanto, a sociedade de forma geral, repudia o uso de algumas drogas, com ações estatais que incessantemente reprime a venda e o uso de substâncias psicoativas ilícitas, desta forma a população tem a falsa impressão que o Estado promove a segurança de seus cidadãos (Galvão \& Martins, 2013). Por outro lado, as práticas exercidas pelo estado apontam um esgotamento do modelo de repressão, pois, o poder de força que o Estado usa para sanar a questão das drogas, mais os problemas relacionados a ela abundam, como alargamento da escala de violência institucional, sofrimento, criminalização e massacre de populações minorizadas (Ribeiro, 2013).

$\mathrm{O}$ interesse pelo tema do proibicionismo surgiu durante o transcorrer do curso de Pós Graduação de Saúde Mental, na disciplina de Álcool e outras drogas, pelo fato da lógica proibicionista ter um discurso em torno do uso e prevenção às drogas e concomitantemente com uma política repressiva, com isso gerando inquietação sobre os efeitos que esta lógica gera sobre a vida das pessoas que fazem uso destas drogas que são proibidas.

A relevância deste trabalho se dá na medida em que a lógica proibicionista é muito explorada, uma vez que as políticas na maioria dos países - e também no Brasil,- são regidas por esta perspectiva e por serem bem divulgadas nos meios de comunicação, mas pouco se sabe sobre o impacto que esta lógica acarreta na vida das pessoas, principalmente as menos favorecidas. Sendo assim, acredito que este trabalho tem muito a contribuir academicamente, uma vez que, a droga historicamente sempre esteve presente na humanidade e o seu uso repercute na saúde mental dos indivíduos. E muito a contribuir socialmente, já que pode ajudar com reflexões junto a usuários de drogas ilícitas; demais profissionais da área da saúde como os trabalhadores da atenção básica, agentes de saúde e conselheiros de saúde. Este trabalho também é relevante para os (as) Psicólogos (as) que estão atuantes nas políticas públicas, a fim deque possam ampliar o referencial teórico, bem como refletir a sua visão de homem e de mundo que sustenta sua prática.

Este trabalho teve como objetivo geral conhecer o sofrimento e a violência que a lógica proibicionista gera na vida de usuários de drogas ilícitas, e como objetivos específicos compreender o quanto o proibicionismo repercute na saúde mental dos usuários e usuárias de drogas ilícitas; identificar o quão esta lógica produz violência na vida das pessoas que fazem uso destas drogas; analisar o sofrimento existencial do usuário de droga e por fim, aprofundar o conhecimento sobre fenômeno das drogas ilícitas. 
A metodologia utilizada foi uma revisão bibliográfica, de cunho qualitativo. A literatura pesquisada inclui livros, artigos, legislação pertinente na atenção a usuários de álcool e outras drogas no Brasil, teses e dissertações, pesquisas realizadas nas bases de dados Literatura Latino-Americana e do Caribe em Ciências da Saúde (LILASC), Scientific Electronic Library Online (SCIELO), no banco de teses/dissertações da Coordenação de Aperfeiçoamento de Pessoal de Nível Superior (CAPES) e no banco de dados das Universidades Federais. O analisado se dá do período de 2013 à 2017.

\section{Proibicionismo: 0 Consumo, a Proibição de Drogas e a Violência}

O uso de substâncias psicoativas é tão antiga quanto à própria humanidade, embora algumas substâncias nem sempre tenham existido (Karam, 2008). Segundo Freitas (2016) durante séculos, os seres humanos conviveram com as substâncias de forma bastante tranquila, apesar de ter registros na antiguidade conflitos do uso de álcool e ópio.

As substâncias psicoativas tornaram-se um problema recentemente no século XIX quando surge à guerra ao ópio, um conflito entre Reino Unido e China. O Reino Unido queria o livre comércio na China; esse momento é a primeira guerra contra droga (Ribeiro, 2013). Muito embora, a proibição nesse momento tenha sido de interesse econômico, em outros momentos da história teve-se proibição por questões morais religiosas como foi o caso de certas pomadas e poções que eram vistos como bruxaria na época da inquisição (Sodelli, 2010).

Alguns anos mais tarde, os EUA determinou que a cocaína e o ópio fossem utilizados apenas com prescrição médica, posteriormente o uso recreativo foi colocado na ilegalidade, cabendo ao médico à autorização do consumo de psicotrópicos (Ribeiro, 2013). Para Rodrigues (2008, p. 94), o "controle para uso médico" não desaparecia sob as camadas do discurso criminal, deixando antever que o tema das drogas ilícitas era entendido como um "problema sanitário" agravado pelo mercado ilegal, a ser coibido pela ação policial e da justiça criminal".

O proibicionismo foi a adoção de medidas de interdição e repressão do consumo de certas substâncias psicoativas que passou a ocorrer desde o final do século XIX no mundo ocidental, especialmente nos Estados Unidos e que, a partir do século XX, se tornou uma política mundial por meio de acordos e tratados internacionais (Oliveira \& Carneiro, 2014, p. 23).

Como o pensamento proibicionista repercutiu mundo a fora, no Brasil não foi muito diferente. A história das drogas no Brasil começa com o 
"uso pelos indígenas de muitas plantas medicinais e psicoativas, incluindo o tabaco, e dos cauins, fermentados de mandioca e de frutas, a ipecacuanha, a copaíba, a quina, a jurema, são algumas dessas plantas de usos tradicionais" (Oliveira \& Carneiro, 2014, p. 20). Ou seja, a proibição no Brasil nasce inicialmente com a abolição da escravatura, em 1988, como forma de controlar a cultura negra que lutava para fazer parte do tecido social existente (Lunardon, 2015).

Nas primeiras décadas de 1900 torna-se evidente o crescimento do uso de maconha, até que em 1921 criminaliza o uso da maconha no território brasileiro, com o Decreto Federal 4294, mas só em 1932 que se torna explícito o uso de substâncias entorpecentes em geral (Lunardon, 2015). Num período de quase meio século foram implantadas inúmeras alterações legislativas com nítida preocupação sanitarista, assumidas em convenções internacionais, o que terminou por instaurar um sistema médico-policial (Ribeiro, 2013). Atualmente a que vigora no Brasil é a Lei 11.343/06 (Ministério da Saúde, 2006). Diante disso Sodelli (2010, p. 52) acredita que "a postura proibicionista tem duas áreas de atuação: acabar com a produção, 0 cultivo e o tráfico de drogas no mundo, isto é, acabar com o consumo de drogas ilegais no mundo", onde o uso das drogas tem uma associação dualista de bem e mal, certo e errado (Sodelli, 2010).

O modelo proibicionista-punitivo tem por fundamento dois princípios: um de ordem moral-religiosa, que prega a abstinência como única possibilidade relacional dos indivíduos com essas substâncias, e outro de ordem higienista, que preconiza o ideal de um mundo livre de drogas, que, conjugados, determinam a proibição de qualquer modalidade de seu uso, comércio, ou produção dos psicotrópicos etiquetados como ilícitos (Ribeiro, 2013, p. 26).

Na compreensão do historiador Henrique Carneiro (citado por Rocha, 2013 , p. 8) a guerra às drogas permite um controle estatal, pois o "Estado investido do poder de polícia mental e comportamental, que legisla sobre os meios botânicos e químicos de que os cidadãos se utilizam para interferir em seus estados de humor e de consciência e que pune os que desobedecem (...)".

Noutras palavras, a guerra às drogas é geradora de violência, tendo em vista que a "violência é entendida como violação de algo, é sempre um ato de transgressão ou de imposição de uma ordem préestabelecida, de ruptura ou imposição, pela força (explícita, implícita ou simbólica), de um sentido social pré-definido" (Tavares, 2013, p. 83), e que "a violência supõe a existência de relações assimétricas entre os indivíduos, grupos sociais, entre Nações ou entre as instituições do Estado e os cidadãos" (Tavares, 2013, p. 83). 
Dito de outro modo, a etiologia da palavra Violência é latina, da palavra vis, quer dizer força e se refere às noções de constrangimento e de uso da superioridade física sobre o outro, os eventos violentos se referem a conflitos de autoridade, a lutas pelo poder e a vontade de domínio, de posse e de aniquilamento do outro ou de seus bens (Minayo, 2005).

Logo, como as práticas derivadas do modelo proibicionista são pautadas na intolerância e repressão, objetivando o fim da produção, assim como o fim de todo e qualquer drogas ilícitas (Sodelli, 2010), essa lógica termina desembocando num estado policialesco, consequentemente criando, com a proibição, riscos a saúde física e mental dos cidadãos que eventualmente venham consumir as substâncias ditas ilícitas (Ribeiro, 2013; Sodelli, 2010; Tavares, 2013).

Seguindo essa análise, o psicólogo existencialista Rollo May (1974), fala de uma violência vinda de cima. Para ele, a violência vinda de cima ocorre quando um grupo no poder usa o mesmo para manter ou reestabelecer o status quo. Ele concebe o poder como a capacidade de causar ou impedir mudanças, onde possui duas dimensões, uma é o poder como potencialidade, de ser capaz; e a outra o poder em ação, o poder exercido (May, 1974).

Na guerra as drogas ilícitas, o usuário de substâncias ilícitas é visto como inimigo, como explicita Rollo May (1974, p. 121), em "qualquer guerra, (...) apressadamente transformamos o inimigo na imagem do demoníaco", acrescenta Karam (2013), a proibição às drogas cria crimes sem vítima. Para Rollo May (1974) a violência praticada por alguém que detém o poder, é, a violência que vem de cima, é uma violência destrutiva, em razão de acreditar que o indivíduo se utiliza os poderes individuais com o objetivo de comprovar um poder maior. Assim, para Rollo May (1974) a guerra corrói a responsabilidade individual e a autonomia de consciência, na medida em que a declaração de guerra é importante como afirmação moral, como justificativa moral, e possibilita ao soldado transferir sua responsabilidade para o seu uniforme.

Do ponto de vista de Karam (2013, p. 45), o alvo primordial da guerra às drogas é claro: "traficantes" das favelas e aqueles que, pobres, não-brancos, marginalizados, desprovidos de poder, a eles se assemelham são os "inimigos". Vale frisar, não é só o Estado gerador de violência, os meios de comunicação também abordam o tema de maneira alarmista e sensacionalista, por meio de clichês, informações e conhecimentos pouco confiáveis, com isso contribuindo para o aumento do preconceito e da intolerância aos usuários de drogas ilícitas (Sodelli, 2010).

Nesse sentido, "os meios de comunicação reproduzem e legitimam o discurso da classe dominante" (Sodelli, 2010, p. 68). Pois, para autores como Karam (2013), Sodelli (2010) e Tavares (2013), é mais 
lucrativo e menos custoso, responsabilizar o uso de drogas por todas as mazelas do mundo, tais como pobreza, desemprego, desigualdade social, etc. Uma das consequências direta disso é que as pessoas utilizam drogas e não causam problemas para a sociedade terminam se escondendo e negando seu uso, principalmente por medo de serem estigmatizados e legalmente punidos (Sodelli, 2010). E não só isso, ela limita o potencial humano, assim diz Rollo May (1974, p. 172):

A violência é um sintoma, carência de poder, insignificância, injustiça, uma vez que, o poder é direito de todo o ser humano, adquirido desde o nascimento. É fonte de sua autoestima e a raiz da convicção de que ele significa alguma coisa no plano interpessoal.

\section{Fundamentos Fenomenológicos Existenciais e o Sofrimento Existencial}

O ser humano constantemente é confrontado com questões existenciais como liberdade, escolha, angústia, responsabilidade, finitude, dentre outros; com isso, o homem atribui significado a sua existência e ao mundo, isto é, um sentido. E como a existência se torna uma ação singular, particular e subjetiva. O existir significa muito mais que apenas um acontecimento intelectual; como engajamento pessoal pressupõe uma unidade de pensar, querer, agir e sentir (Amorim, 2014). Pois, só a condição humana é capaz de refletir sobre suas ações, afetando e sendo afetado pelo seu meio, haja visto que o homem é um ser de linguagem, que se expressa tanto verbalmente como corporalmente como já bem dizia Heidegger (citado por Amatuzzi, 2010, p. 9): "não é a linguagem que se encontra no homem, mas o homem que se encontra na linguagem".

A linguagem é expressa de vários modos, na guerra às drogas é explícito com um discurso alarmista, quando não terrorista, além de assumir posturas diferentes nos diferentes grupos sociais (Torcato, Soares, Corradi-Webster, Carneiro, \& Adorno, 2013). Dessa forma, tal guerra mobiliza sentidos às experiências internas e externas, influenciando nas escolhas do indivíduo, considerando a escolha e o ser de cada realidade humana (Erthal, 1999). Dado que, cada modo de ser expressa a escolha original desta realidade, junto a isso, a imagem que o indivíduo tem de si mesmo é afetada por esta mesma realidade, isto é, valores e crenças são influenciados pelo mundo que o cerca.

Desse modo, a fenomenologia existencial humanista concebe o ser humano como ser orientado para o crescimento, dinâmico, com potencialidades individuais e uma tendência à atualização; ratifica 
Critelli (1996), a experiência humana da vida é, originariamente, a experiência da fluidez constante, da mutabilidade.

A tendência a atualização é a mais fundamental do organismo em sua totalidade. Preside o exercício de todas as funções, tanto físicas quanto experiênciais. E visa constantemente desenvolver as potencialidades do indivíduo para assegurar a sua conservação e seu enriquecimento, levando-se em conta as possibilidades e os limites do meio (Rogers, 1977, p.43).

Nesse sentido, a lógica proibicionista vai em direção oposta à tendência a atualização e ao potencial do indivíduo, na medida em que o indivíduo não toma consciência de seus sentimentos e significações pessoais, ou seja, estes não são reconhecidos, possuídos ou expressos (Rogers, 1981), Rogers chama de incongruência. A incongruência é gerada pelo organismo como uma forma de responder as vivencias geradoras de ameaças, estas acabam sobrepondo a autenticidade do indivíduo, a segurança e a autoestima, como esclarece Erthal (1999, p. 66): "embora as defesas que o organismo utiliza preservem a identidade e o sentido de valor pessoal de casa um, têm a desvantagem de não serem adaptáveis no sentido de lidar realisticamente com os problemas". Isto é, no modo incongruente o indivíduo tem um desencontro consigo próprio, onde 0 eu acaba por se submeter às regras do outro.

Em contrapartida, agir de modo congruente significa que os sentimentos que o indivíduo estiver expressando são válidos para ele, para sua consciência e ele pode viver esses sentimentos, assumi-los e comunica-los se for o caso. Em razão do homem refletir suas experiências, e sendo esta sua essência, o ser humano não pode fugir a sua liberdade tendo em vista que ser livre é escolher, mesmo que dentro dos limites de suas possibilidades (Erthal, 1999).

Nesse mesmo sentido, a decisão de usar ou não usar drogas ilícitas é de responsabilidade do indivíduo, um modo do indivíduo estar no mundo. Por vezes, o uso de drogas pode proporcionar um modo mais agradável de estar no mundo e os desdobramentos dessa experiência dependerá da relação que o sujeito estabelece com a substância (Sodelli, 2010).

Contudo, a guerra às drogas não leva em consideração a condição humana de ser livre, responsável e dono de sua existência (Heidegger, 2005). No entendimento de Kierkegaard (2010) as palavras proibição seguem-se da sentença: "certamente tu morrerás". Essa relação desperta no indivíduo uma ameaça de castigo que tem uma representação assustadora, sendo geradora de angústia já que, "a infinita possibilidade de ser-capaz-de, que a proibição despertou, aproxima-se ainda mais porque esta possibilidade manifesta outra possibilidade como consequência" 
(Kierkegaard, 2010, p. 48). O não viver de modo congruente favorece o obscurecimento, encobrimento, obstruções no modo de ser (Heidegger, 2005a), com isso levando o indivíduo a negar e reprimir sentimentos que podem parecer anormal ou vergonhoso, noutras palavras, levando-o a entrar num processo de rotulação de si, consequentemente, sofrimento existencial. O sofrimento é um fenômeno que faz parte da condição existencial humana, imanente à experiência vivida, possui um sentido, que se manifesta no modo de ser e de estar com os outros. Ele nos marca e nos faz sofrer.

O sofrimento humano nunca é objetivável, não existe parâmetro algum de comparação com a disfunção de um sistema determinístico causal, seja de natureza orgânica ou mecânica. Há uma diferença ontológica radical entre o fenômeno da dor fisiológica, tal como objetivada pela biologia, e a experiência humana de sofrimento. (...) ele possui uma motivação, um sentido, que emerge de uma experiência de si e do mundo, na maioria das vezes de modo irrefletido (Sá, 2014, p.5).

Rogers (1981) acredita que o sofrimento existencial é a negação da experiência organísmica, pelo fato de temer a perda de afeto, de poder, de status, enfim, de qualquer que seja a necessidade do indivíduo. Assim sendo, o indivíduo em sofrimento tem uma perda da liberdade, uma limitação da possibilidade de viver (Heidegger, 2005). Haja vista, a questão do uso das drogas ilícitas é uma possibilidade da condição existencial, uma forma de experimentar o mundo e de alterar a consciência, mas o indivíduo que escolhe fazer uso de tais substâncias acaba escondendo e negando o uso por medo de não ser aceito (Sodelli, 2010).

Nesse processo a guerra as drogas, com sua postura repressiva, acaba colocando todos que são usuários de drogas ilícitas na ótica do errado, do doente, do marginal (Karam, 2008; Ribeiro, 2013; Sodelli, 2010). Logo, além do pensamento proibicionista produzir nos indivíduos usuários de drogas ilícitas um entravamento, para que estes possam realizar escolhas livres, com responsabilidade e sem receios de mostrar uma parte do seu eu.

Quando a proibição, ao invés de coibir acaba por estimular um mercado ilícito vigoroso, indivíduos pertencentes a grupos já anteriormente passíveis de vigilância ganham um acréscimo de "periculosidade" porque além dos crimes que poderiam cometer, passa a ser possível um novo crime, tão ameaçador porque é uma afronta ampla à sociedade (Rodrigues, 2008, p. 99). 
Diante disso, o sofrimento existencial é singular a cada indivíduo, uma forma particular de interação com o meio; coloca-se na perspectiva do vivido e lança um sentimento de desamparo. Ou seja, o sofrimento não é simplesmente uma dor, já que a dor pode ser superada, pode ser não pensada, mas, o sofrimento chama a atenção à própria dor que habita no íntimo do indivíduo. A dor, em seu caráter de ser-dor, é uma vivência de perniciosidade ao próprio ser (Costa, 2017).

Desse modo, o proibicionismo gera modos inautênticos de existir, modos inautênticos de pensar (Heidegger, 2005), ou seja, a guerra às drogas produz sofrimento existencial já que o sentido da existência está obscuro, com fixidez dos sentimentos e da experiência, consequentemente, inibição do potencial para o crescimento organísmico. Isto é, impedindo que o indivíduo seja um ser autônomo, que tenha a coragem de dançar a sua própria dança, assumindo o seu pensar, sentir e fazer, que dizer, escolhendo a responsabilidade e liberdade para projetar sua própria vida.

\section{Política de Redução de Danos Enquanto Proposta de I ntervenção Clínica}

Como se sabe, as drogas sempre estiveram presente na sociedade, modificando a forma como cada sociedade lida com a substância. As políticas públicas, por sua vez, incidem diretamente nestes processos sócio-históricos (Adamy \& Silva, 2017). Historicamente, o Brasil é signatário das convenções, tratados e acordos internacionais que em sua origem estão alinhados ao modelo proibicionista, na tentativa de dar conta do consumo de drogas através de normativas jurídicas (Barreto, Souza, Rangel, Muylaert, \& Constantino,2016).

A partir da constatação da falência da estratégia de guerra às drogas e diante do aumento da variedade e do uso de substâncias ilícitas, o Estado brasileiro, apoiado pelos movimentos sociais em prol dos direitos humanos, criou políticas públicas direcionadas às pessoas que usam drogas, principalmente às ilícitas (Machado \& Boarini, 2013). Apontada inicialmente como uma proposta de intervenção, a estratégia de Redução de Danos é considerada uma maneira de reduzir danos decorrentes do uso nocivo de drogas, sem necessariamente levar a abstenção.

Em vista disso, a Redução de Danos é um paradigma. Pois, confronta a lógica proibicionista de diversas formas, que vão desde a postura em relação às drogas, o papel do Estado, até a política de drogas. Isto é:

A redução de danos contrapõe-se, desse modo, ao modelo tradicional, de cunho meramente proibicionista-punitivo, que 
desconsidera a complexidade do fenômeno, buscando uma meta única: a erradicação da produção e consumo das drogas etiquetadas ilícitas. A redução de danos, por seu turno, fundase nos princípios de pluralidade democrática, exercício da cidadania, respeito aos direitos humanos e de saúde (Ribeiro, 2013, p. 46).

Dessa forma Barreto et al. (2016, p. 57) define a Redução de Danos como um "conjunto de medidas em saúde que tem a finalidade de minimizar as consequências adversas do uso/abuso de drogas. Tais ações possuem como princípio fundamental o respeito à "liberdade de escolha", ou seja, levando em conta que o indivíduo não quer ou não tem condições de abdicar da substância, ainda sim podem ser evitados agravos à saúde. Para Lima (2014, p. 33) "prevenir pode ser qualquer atitude que propicie experiências para que o sujeito responsabilize-se pela sua existência".

Segundo Lindner e Siqueira (2016), a ideia de Redução de Danos surge no Brasil em Santos, São Paulo, no final da década de 1980, quando crescia a transmissão de doenças sexualmente transmissíveis pelo uso de drogas injetáveis. Na compreensão de Ribeiro (2013) o advento da lei paulista foi marco inicial da Redução de Danos no Brasil, já que as estratégias de Redução de Danos foram legitimadas e assumidas como política pública.

Para Costa e Teles (2017), enquanto política pública, a redução de danos é considerada uma abordagem horizontal na relação do cuidado, uma vez que, na relação entre profissional e usuário de drogas não existe a premissa de superioridade. Ainda segundo eles (Costa \& Teles, 2017), o próprio usuário deve tomar a iniciativa na estruturação de estratégias para cuidar de sua saúde, junto com instâncias políticas de gestão em saúde no desenvolvimento de programas, como resultado promove o acesso a serviços de baixa exigência e de baixo custo.

O novo modelo criou o ambiente jurídico-político adequado para que a política de drogas pudesse se concentrar nas ações de prevenção e educação, redução de danos, ampliação e melhoria dos programas de tratamento e em atividades que ajudassem grupos de risco ou consumidores de drogas a manter ou restaurar as suas relações familiares, laborais e sociais (Ribeiro, 2013, p. 105).

Na realidade, as estratégias de Redução de Danos são aplicações de práticas que proporcionam condições para a atuação responsável do usuário e o exercício de seu direito de escolha por meio da flexibilização dos métodos (Conte et al., 2006 como citado em Fortesk e Faria ( 2013). Visto que, a estratégia de Redução de Danos tinha como primeira ação emblemática o fornecimento e troca de seringas, dando voz e vez aos usuários, considerando o contexto e o significado para cada indivíduo que faz uso de substância ilícita; 
consequentemente permitindo-se que possa ocorrer a criação do vínculo e da comunicação (Linder \& Siqueira, 2016).

Com isso, a intervenção clínica, nesse contexto, pressupõe estar junto, estar disponível, acompanhar, ou seja, escutar. Assim, "acompanhar em saúde supõe, a escuta do desejo do outro de por onde ele quer andar. E esse andar pressupõe diferentes andares, que podem mudar a cada instante e a cada nova potência de vida que se abre" (Adamy \& Silva 2017, p. 149). Nesse sentido, a proposta de Redução de Danos permite construir com o indivíduo, possibilidades de escolhas mais congruentes e mais livres, diminuindo as distâncias sociais entre os sujeitos e com isso diminuindo o sofrimento existencial, visto que, o indivíduo descobre-se experienciando plenamente seus sentimentos na relação e, a medida que os vive de forma variada, depara-se com o seu comportamento mudando de forma construtiva, em concordância com o seu eu, onde vivenciando a experiência (Rogers, 1981).

E como desdobramento, a política de Redução de Danos oportuniza o usuário de substâncias ilícitas estabelecer vínculos com os serviços públicos de saúde, além de proporcionar que estes mesmos indivíduos possam perceber-se como sujeitos de direitos, já que, o Estado tenta garantir a estes grupos que vem sendo discriminados, seja pelo isolamento, seja pelos maus tratos recebidos, e consequentemente possam receber cuidado e tratamento adequados (Kinoshita, 2013).

Nessa sequência, Sodelli (2013) acredita que esta intervenção junto a usuários traduz maior tolerância ao uso de drogas, compreendendo que existem pessoas que sentem necessidade de usar substâncias ilícitas enquanto outras não, ao mesmo tempo em que, a preocupação está no modo como este consumo é realizado. Por isso Lancetti (2011) entende que em primeiro lugar a Redução de Danos permite a aproximação com esta camada da população para depois intervir com técnicas que estão relacionadas com uma parte muito intima da vida de cada um, que é a sexualidade e uso de drogas.

A ideia é que, o indivíduo vá aprendendo a enfrentar a vida comum com outra perspectiva, aplicando o princípio da Redução de danos, com isso reduzindo o uso de drogas e melhorando a qualidade do consumo (Lancetti, 2011), atentando para os pensamentos e sentimentos envolvidos, aos modos de uso e aos efeitos da substância no corpo e nas relações interpessoais. Na compreensão de Lancetti (2011, p. 62), o tratamento da abstinência proposto pela lógica proibicionista, "parece não trazer mudanças para a vida da pessoa. Ela aprende a ficar abstinente por um tempo, mas ela não está preparada para a vida, então o contato com a vida do jeito que ela é faz com que o sujeito regrida".

Por isso, os maiores riscos e danos relacionados às drogas não são causados por elas mesmas, mais sim pela proibição junto com 0 
apoio midiático (Karam, 2013), que influencia a população com aspectos negativos, ao passo que desconsidera completamente outras possibilidades de relacionar-se com as drogas. De acordo com Heidegger (2005, p. 117) "o sentido é o contexto no qual se mantém a possibilidade de compreensão de alguma coisa, sem que ele mesmo seja explicitado, ou, tematicamente, visualizado", no entanto, é singular a cada indivíduo.

Portanto, em todas as ações de redução de danos devem ser preservadas a identidade e a liberdade da decisão do usuário sobre qualquer procedimento relacionado à prevenção, ao diagnóstico e ao tratamento (Brasil, 2005), isto necessariamente levará a minimização que a violência e o sofrimento produzido pelo proibicionismo imprime na vida dos usuários de drogas ilícitas, já que valoriza a promoção de um mecanismo individual de autocontrole/autorregulação do consumo (Cruz \& Machado, 2013), permitindo que o cotidiano seja preenchido com significados próprios ou novos significados.

A política antiproibicionista vai conduzindo o usuário de drogas ilícitas a desconstruir estigmas e marginalizações causados pela guerra as drogas, notadamente consentindo que o indivíduo sinta-se bem fisicamente e psicologicamente, e o mesmo possa compreender que no momento está em situação de vulnerabilidade, seja ele de cunho individual, social ou político-institucional. Nesse sentido Sodelli (2013, p. 81) esclarece: "a compreensão de que ninguém é vulnerável mais está vulnerável, resultante da dinâmica relação entre os componentes individuais, sociais e programáticos, provoca novas reflexões sobre a prevenção ao uso nocivo de drogas".

Assim sendo, cabe ao profissional, ter uma sensibilidade para considerar os contextos de uso e os fatores psicossociais presentes, para, a partir disso possa elaborar estratégias de cuidado mais próximas da realidade do usuário de drogas ilícitas (Dantas, Cabral, \& Moraes, 2014). Deste modo, a noção de cuidado e autocuidado contextualizadas e compartilhadas, valoriza a autonomia do indivíduo que faz uso de drogas. Com isso, os autores acreditam proporcionar ao usuário reconhecer circunstâncias não favoráveis e deste modo possa então optar pelo não uso numa determinada circunstância, ou pela substituição da droga, ou a diminuição da quantidade, entre outras estratégias (Dantas et al., 2014).

Portanto, a intervenção clínica com os usuários de substâncias ilícitas deve estar coerente com o proposto pela política da Redução de Danos e com a política de Atenção Integral a Usuários de Álcool e Outras Drogas, a fim de ajudar a perceber características e necessidades dos usuários para que então se possa desenhar e implantar múltiplos programas de prevenção, educação, tratamento e promoção adaptados às diferentes necessidades (Brasil, 2003). 


\section{Considerações Finais}

O ideário da lógica proibicionista de um mundo sem drogas é algo intangível já que, faz parte das possibilidades existenciais o uso de drogas, onde a realidade do uso de substâncias drogas ilícitas é muito mais complexa, estando o uso vinculado ao sentido que o indivíduo estabelece com a substância, ou seja, para o indivíduo a substância ocupa um lugar que tem relação com o contexto que o circunda; um contexto vivencial e social.

No entanto, a lógica proibicionista foge totalmente dessa perspectiva, por negar a história dos indivíduos na sua relação com seus consumos, contextos e emoções no decorrer do curso de vida e, com isso, não analisa o fenômeno do consumo das substâncias ilícitas em sua complexidade, se limitando a repressão e a intolerância as drogas tidas ilícitas; repressão esta militarizada por parte do Estado e repressão no discurso, onde coloca a droga como um grande mal e por isso, esta deve ser evitada e erradicada da sociedade.

Esse discurso manipula indivíduos, principalmente as menos esclarecidas, gerando estigmas, sofrimento e violência para os usuários de drogas ilícitas. As consequências dessa lógica na vida dos indivíduos é desastrosa, já que a liberdade existencial é diminuída, primeiro, pelo simples fato do usuário usar a substância e ter medo de assumir o uso com receio de sofrer violência vinda por parte dos representantes estatais, assim como da população ao seu redor; e segundo, por também ter internalizado o discurso proibicionista, o que culmina numa percepção incongruente de si. Isso se intensifica ainda mais quando o é usuário de pobre, negro e que vive na favela.

Comitente a isso, a violência institucional impede que o potencial do indivíduo se desenvolva, impossibilitando o crescimento do indivíduo, ou seja, que este possa desenvolver escolhas mais livres e conscientes, com autenticidade no seu modo de ser e estar no mundo. $\mathrm{Na}$ análise da lógica proibicionista destacamos que, o principal interesse está relacionado ao aspecto econômico das drogas, funcionando, assim, como uma ordem higienista, de controle social. Embora fadado ao fracasso, esse modelo conta com a mídia sensacionalista e alarmista, que propaga os preceitos de intolerância e guerra às drogas. Com efeito, o sofrimento existencial torna-se tangível para os usuários, uma vez que estes experienciam vivências ameaçadoras a autenticidade, a segurança e autoestima.

A compreensão fenomenológica existencial e humanista nos mostrou que o ser humano tem uma tendência ao crescimento, a autonomia, a atualização; mas diante de quaisquer circunstâncias que impede a tomada de consciência dos sentimentos e significações pessoais levam o indivíduo a sentir angustia, medo, rejeição. Ainda por meio da visão fenomenológica existencial foi possível chegar ao 
entendimento da impossibilidade de modificar a condição existencial do homem.

No que tange o uso de drogas ilícitas o entendimento é que o indivíduo é livre para fazer uso de substâncias ainda que estas the tragam danos físicos, embasado nos direitos humanos, tentamos elucidar a proposta de redução de danos enquanto intervenção clínica. Por entender que a abstinência e a repressão não produzem ações redutoras de vulnerabilidade, nem ajuda o usuário a relacionarse com a substância de outro modo, bem como construir uma rede de cuidados. Desta forma a estratégia da redução de danos diminui as distâncias sociais, o sofrimento existencial uma vez que, o indivíduo se vê expressando de forma congruente. Entendemos e defendemos que a Redução de Danos é melhor caminho para prática do cuidado junto aos usuários de drogas, por verificar ser possível através da escuta, do respeito e da liberdade, resgatar o que perpassa no íntimo do indivíduo, refletindo sua verdade, e assim trazendo novas possibilidades existenciais. Compete ao profissional questionar-se que tipo de sofrimento o usuário está vivendo, como são os vínculos, o que o indivíduo mostra para além do uso de drogas.

\section{Referências}

Adamy, P., \& Silva, R. (2017). Redução de danos e linhas de cuidado: Ferramentas Possíveis para o Cuidado em Saúde Mental, Álcool e Outras Drogas. In S. Torossian, S. Torres, D. Keveller, (Orgs), Descriminalização do cuidado: políticas, cenários, experiências em redução de danos (pp. 145-158). Porto Alegre: Rede Multicêntrica.

Amatuzzi, M. (2010). Pesquisa Qualitativa e Pesquisa Fenomenológica. In F. Klocner (Org), A Abordagem Centrada na Pessoa: a Psicologia Humanista em Diferentes Contextos (pp. 225-233). Londrina: Unifil.

Amatuzzi, M. (2010). Por uma psicologia mais humana. São Paulo: Alínea.

Amorim, M. (2014). Reflexões Sobre a Obra Kierkegaardiana: o Desespero Humano (Monografia não publicada). Universidade Estadual da Paraíba, Campina Grande, Paraíba, Brasil.

Barreto, B., Souza, P. M. S., Rangel, Y., Muylaert, H., \& Constantino P. (2016). Clínica Nômade Voz da Rua: Políticas de Drogas e Redução de Danos. Perspectivas On Line: Humanismo e Sociais Aplicada, 16(6), 53-58.

Branco, J. (2013). Violência Entre Ontologia e História da Filosofia de J ean-Paul Sartre. Revista Kínesis, 5(10), 288-304. Recuperado de 
https://www.marilia.unesp.br/Home/RevistasEletronicas/Kinesis /judikael.pdf

Brasil. Ministério da Saúde. (2003). A Política do Ministério da Saúde para atenção integral a usuários de álcool e outras drogas. Brasília: Ministério da Saúde, 2003.

Brasil. Ministério da Saúde. (2006). Lei № 11.343, de 23 de Agosto de 2006. Dispõe medidas para prevenção do uso indevido, atenção e reinserção social de usuários e dependentes de drogas; estabelece normas para repressão à produção não autorizada e ao tráfico ilícito de drogas e dá outras providencias. Recuperado de http://www. planalto.gov.br/ccivil_03/_ato20042006/2006/lei/l11343.htm

Costa, B., \& Telles, T. (2017). O Processo de Escuta na Redução de Danos: Contribuições de Rogers e Kierkegaard. Revista da Abordagem Gestáltica, 23(1), 74-83. Recuperado de http: // pepsic. bvsalud.org/scielo. php?script=sci_arttext\&pid=S1 809-68672017000100009

Costa, B. A. (2017). Sofrimento e Existência: uma Leitura Daseinsanalítica. Revista Latinoamericana de Psicoterapia Existencial Un Enfoque Comprensivo Del Ser, 7(14), 11-18. Recuperado de http://www.fundacioncapac.org.ar/REVISTA_14_final.pdf

Critelli, D. M. (1996). Analítica do sentido: uma aproximação e interpretação do real de orientação fenomenológica. São Paulo: Brasiliense.

Cruz, O., \& Machado, C. (2013). Intervenção no Fenômeno das Drogas: algumas Reflexões e Contributos para a Definição de Boas Práticas. Psicologia, 27(1), 13-31. Recuperado de http: //www.scielo.mec.pt/scielo.php?script=sci_abstract\&pid=S 0874-20492013000100002\&lng =pt\&nrm =iso

Dantas, S., Cabral, B., \& Moraes, M. (2014). Sentidos produzidos a partir de experiências de badtrip: drogas, prevenção e redução de danos. Saúde em Debate, 38(102), 539-550. doi: 10.5935/0103-1104.20140050

Erthal, T. (1999). Terapia Vivencial: uma Abordagem Existencial em Psicoterapia. Rio de Janeiro: Vozes.

Forteski, R., \& Faria, J. (2013). Estratégias de Redução de Danos: um exercício de equidades e cidadania na atenção a usuários de drogas. Revista de Saúde Pública de Santa Catarina, 6(2), 7991.

Recuperado

de http://revista.saude.sc.gov.br/index. php/inicio/article/view/169 1215

Freitas, L. (2016). O abuso de substâncias psicoativas enquanto fator de impacto no contexto das relações familiares: uma Revisão sistemática entre 2005 e 2015 (Dissertação de Mestrado não 
publicada). Universidade Federal de Santa Catarina, Florianópolis, Santa Catarina, Brasil.

Galvão, M., \& Martins, T. (2013). Criminalização da Pobreza: o Produto de uma Violência Estrutural. Transgressões: Ciências Criminais em Debate, 1(2), 42-65. Recuperado de https: //periodicos.ufrn.br/transgressoes/article/view/6576/508 9

Gorgulho, M. (2012). Drogas e Sociedade. In Conselho Regional de Psicologia 6ạ Região (Org.), Álcool e Outras Drogas (pp. 23-33). São Paulo: CRP-SP. Recuperado de http://crpsp.org/fotos/pdf2015-10-02-17-16-04.pdf

Heidegger, M. (2005). Ser e Tempo (15a ed., M.S. C. Schuback, Trad.). Rio de Janeiro: Vozes.

Karam, M. (2013). Direitos Humanos, Laço Social e Drogas: por uma política solidária com o sofrimento humano. In Conselho Federal de Psicologia (Org.), Drogas, Direitos Humanos e Laço Social (pp. 33-51). Brasília: CFP.

Karam, M. (2008). A Lei $11.343 / 06$ e os repetidos danos do proibicionismo. In B. Labate, S. L. Goulart, M. Fiore, E. MacRae, $\&$ H. Carneiro (Orgs.), Drogas e Cultura: Novas Perspectivas. Salvador: EDUFBA.

Kierkegaad, S. (2010). O Conceito de Angústia (A. L. M. V., Trad.). Rio de Janeiro: Vozes.

Kinoshita, R. (2013). Política Atual de Álcool e outras Drogas e Perspectivas. In Conselho Federal de Psicologia (Org.), Drogas, Direitos Humanos e Laço Social (pp. 53-82). Brasília: CFP.

Lancetti, A. (2011). Clínica Peripatética (6aed.). São Paulo: HUCITEC.

Lima, A. (2014). As Múltiplas Faces do Crack: da Experiência do Usuário ao Contexto Sócio/Político (Dissertação de Mestrado não publicado). Universidade Católica de Pernambuco. Recife, Pernambuco, Brasil.

Lindner, L., \& Siqueira, D. (2016). Redução de Danos: Como foi? O que é possível? O que é preciso? In A. Souza et al. (Org.), Entre Pedras e Fissuras. São Paulo: HUCITEC.

Lunardon, J. (2015). Ei, Policia, Maconha é uma Delícia!! Proibicionismo das Drogas como uma Política de Criminalização Social (Dissertação de Mestrado). Universidade Federal do Rio Grande do Sul, Porto Alegre, Rio Grande do Sul, Brasil.

Machado, L., \& Boarini, M. (2013). Políticas Sobre Drogas no Brasil: a Estratégia de Redução de Danos. Psicologia: Ciência e Profissão, 33(3), 580-595. doi:10.1590/S141498932013000300006

Masur, J., Carlini, E. (1993). Drogas: Subsídio para uma Discussão. São Paulo: Brasiliense.

May, R. (1974). Poder e Inocência (R. Machado, Trad.). Rio de Janeiro: Arte Nova S.A. 
May, R. (2000). A descoberta do Ser: Estudo sobre a Fenomenologia Existencial (C. G. Somogyi, Trad.). Rio de Janeiro: Rocco.

Minayo, M. (2005). Pesquisa Social: Teoria, Método e Criatividade. Petrópolis, RJ : Vozes.

Oliveira, W., \& Carneiro, H. (Orgs.). (2014). Álcool e outras drogas: da coerção e coesão. Florianópolis: Departamento de Saúde Pública/UFSC.

Ribeiro, M. (2013). Drogas e redução de danos: os direitos das pessoas que usam drogas. São Paulo: Saraiva.

Rocha, A. (2013). Proibicionismo e a criminalização de adolescentes pobres por tráfico de drogas. Serviço Social e Sociedade, (115), 561-580. doi: 10.1590/S0101-66282013000300009

Rodrigues, T. (2008). Tráfico, guerra, proibição. In B. Labate, S. L. Goulart, M. Fiore, E. MacRae, \& H. Carneiro (Orgs.), Drogas e Cultura: Novas Perspectivas. Salvador: EDUFBA.

Rogers, C. (1981). Tornar-se Pessoa. São Paulo: Martins Fontes.

Rogers, C. (1977). Psicoterapia e Relações Humanas (2a ed.). Belo Horizonte: Interlivros.

Sá, R. (2014). Considerações fenomenológico-existenciais sobre as relações entre filosofia e psicoterapia. Ekstasis: revista de hermenêutica e fenomenologia, 3(2), 74-87. doi: 10.12957/ek.2014.14078

Sodelli, M. (2010). Uso de Drogas e Prevenção: da Desconstrução da Postura Proibicionista às Ações Redutoras de Vulnerabilidade. São Paulo: IGLU.

Tavares, M. (2013). As Teias da violência: silêncios, invisibilidade e cumplicidades. Faz Ciência, 15(22), 79-101. Recuperado de http://erevista.unioeste. br/index. php/fazciencia/article/view/9146

Torcato, C. E. M., Soares, C. B., Corradi-Webster, C. M., Carneiro, H. S., \& Adorno, R. C. F. (2013). Drogas e Sociedade. Saúde \& Transformação Social, 4(2), 178-7085. Recuperado de http://incubadora. periodicos. ufsc. br/index. php/saudeetransfor macao/article/view/2301/2617

UNODC - Nações Unidas: Escritório sobre Drogas e Crime. (2015). O Relatório Mundial sobre Drogas. Recuperado de https://www. unodc. org/unodc/index. html?ref=menutop

Xiberras, M. (1989). A Sociedade Intoxicada. Lisboa: Instituto Piaget.

\section{Endereço para correspondência}

Bárbara Santos Bernardino da Silva

Rua Uruguaiana, 348 apto 01, I putinga, CEP 50731-220, Recife - PE, Brasil

Endereço eletrônico: barbarasantos.psi@gmail.com

Paulo J osé Barroso de Aguiar Pessoa

Rua Abraham Lincoln, 141 apto 702, Parnamirim, CEP 52060-190, Recife - PE, Brasil

Endereço eletrônico: psipaguiar@gmail.com 
Recebido em: 08/01/2019

Reformulado em: 15/01/2019

Aceito em: 15/04/2019

\section{Notas}

* Psicóloga e Pós-graduada (lato sensu - Especialização) em Psicologia no Âmbito da Saúde Mental com Ênfase na Atenção e no Uso Prejudicial de Álcool e Outras Drogas e Serviços pela Faculdade Frassinetti do Recife - FAFIRE.

** Docente da Pós-Graduação em Psicologia no Âmbito da Saúde Mental com Ênfase na Atenção e no Uso Prejudicial de Álcool e Outras Drogas e Serviços pela Faculdade Frassinetti do Recife - FAFIRE.

Este artigo de revista Estudos e Pesquisas em Psicologia é licenciado sob uma Licença Creative Commons Atribuição-Não Comercial 3.0 Não Adaptada. 